\title{
Best practices in the field of specific risk evaluation of pyrotechnic entertainment articles subject to legal and illegal market surveillance
}

\author{
Bogdan Garaliu-Busoi ${ }^{1 *}$, Daniela Carmen Rus ${ }^{1}$, Claudia Miron ${ }^{1}$, Olga Miclea $^{1}$, and Dan \\ Pintilie $^{2}$ \\ ${ }^{1}$ National Institute for Research and Development in Mine Safety and Protection to Explosion - \\ INSEMEX Petrosani, Department of Safety of Explosion and Pyrotechnic Articles, G-ral V. Milea \\ Street 32-34, Petrosani, Romania \\ ${ }^{2}$ University of Petrosani, Doctoral School, Universitatii Street 22, Petrosani, Romania
}

\begin{abstract}
The field of pyrotechnic articles is very popular and developed, and as a result, the influx of pyrotechnic articles on the market is abundant. However, it should be noted that in addition to compliant products, which meet the applicable essential safety requirements covered by Directive no. 2013/29 / EU, there are also products on the market that can present a significant level of danger when used, handled, transported or stored. Market surveillance authorities frequently find non-compliant products such as pyrotechnic articles offered to the public, some on the legal market, others traded illegally. The establishment of presumptive risks related to pyrotechnic articles can be achieved by applying documented and accredited procedures at national and European level by specialized laboratories, one of these being found within INSEMEX. Technical-scientific expertise activity aims to verify the level of security for products considered suspicious. We have an international collaboration with European authorities, and at the national level, requests for products such as pyrotechnic articles are sent for expertise by the police, the prosecutor's office or the courts. It was found that most products considered "suspicious" had serious deficiencies that could lead to major risks, and those traded illegally lead to considerable economic losses.
\end{abstract}

\section{Introduction}

The field of pyrotechnic articles is very popular and developed, and as a result, the influx of pyrotechnic articles on the market is plentiful.

The faults (nonconformities) that can be identified in pyrotechnic articles may result from the manufacturing process and a superficial quality control at the manufacturer, or may be due to improper storage or handling. These defects, in many cases, can be detected by visual inspection, and in others at the time of the test to verify operation.

The establishment of presumptive risks related to pyrotechnic articles can be achieved by applying documented and accredited procedures at national and European level by specialized laboratories, one of these being found within INSEMEX [1].

\footnotetext{
* Corresponding author : bogdan.garaliu@insemex.ro
} 
As a result of the identification of major or critical non-conformities, the authorities shall order the withdrawal from the market of products consignments with such defects so as not to endanger the safety of persons, property or the environment. To be more precise, the matter of market surveillance cooperation to address this issue seems to be challenging; for example, as mentioned already, requesting authorities in other countries to remove traders, or identifying the relevant official in the police service or similar relevant authority to commence building a case against an illicit trader have been noted as difficult [2].

For this process to be impartial, testing of pyrotechnic articles must be performed by accredited, third-party laboratories. In Europe, not all countries have such laboratories with adequate facilities, but in Romania, INSEMEX Petrosani has made efforts, in terms of material equipment and qualified personnel also.

The purpose of this paper is to highlight the risks presented by the placing on the market and use by unauthorized persons of pyrotechnic articles of suspicious origin.

\section{Procedures for assessing the non-conformity of pyrotechnic articles}

\subsection{Visually identifiable nonconformities of pyrotechnic articles}

Failure to include the pyrotechnic articles in the specification, in terms of calibres or other essential construction dimensions, may give rise to a risk of defective launching or explosion on the ground [2].

The initiation system integrity, whether of a pyrotechnic (fuse) or electrical nature, is a critical non-compliance and the products found to be defective must be rejected and destroyed, with no reasonable possibility of fixing them.

Another non-compliance to be checked is the deformation or alteration of the packaging which may constitute an increased risk of explosion on the ground or launching on an incorrect trajectory of the effect, being applicable especially to missiles, Roman candles, shells or batteries.

Another risk that can affect pyrotechnic articles during transport or storage and that can be visually checked is the accumulation of excess moisture, which can lead to a total malfunction, incorrect or dangerous operation, or to combustion parameters outside acceptable range.

The figure shows typical examples of non-conformities that can be found after visual examination, in all these situations the actual test of the product will be abandoned.

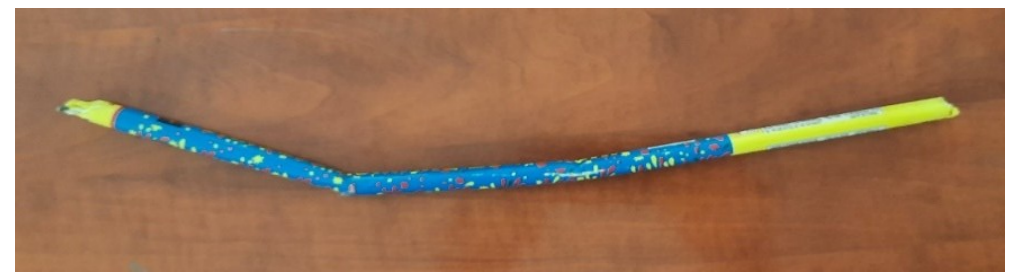

a) Damaged Roman candle body - scrap 


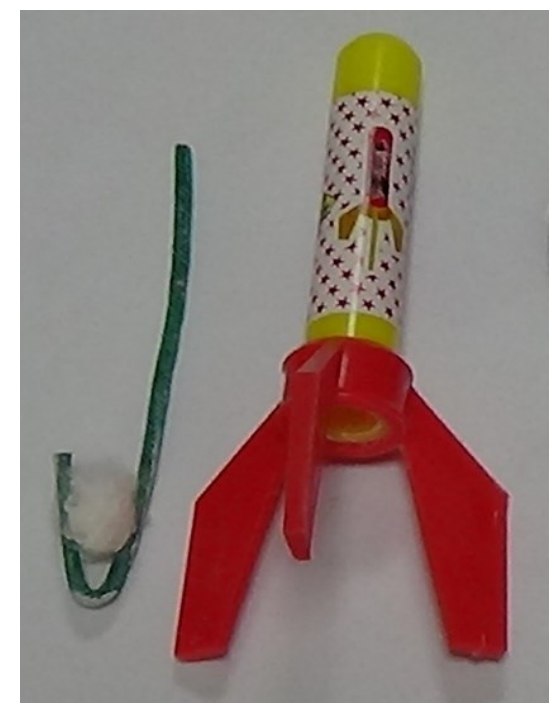

b) Missile launcher system detached from its body - scrap

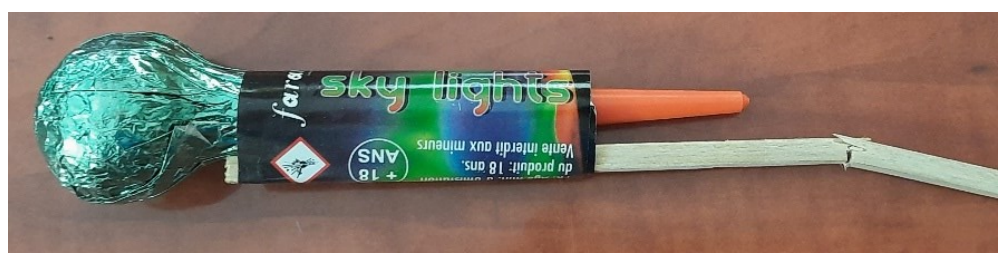

c) Damaged flight stabilizer stick at the rocket - scrap

Fig. 1. Visually identified non-conformities of pyrotechnic articles

\subsection{Nonconformities regarding the pyrotechnic composition.}

Verification of the pyrotechnic composition is important, as deviations from the net amount of explosive material (NEC) may lead to the maximum permissible for a certain category or type of pyrotechnic article being exceeded. For example, depending on the category to which the pyrotechnic article belongs, the net content of explosives may be [3]:

- batteries and combinations category F2 - must not have a net explosive content greater than $500 \mathrm{~g}$; the net explosive content for a combination containing fountains shall not exceed $600 \mathrm{~g}$, of which articles other than fountains shall not exceed 500 $\mathrm{g}$; the net explosive content of a battery containing fountains shall not exceed 600 g. Firecrackers used in batteries or combinations shall not have a total net explosive content of more than $100 \mathrm{~g}$.

- batteries and combinations category F3 - must not have a net explosive content greater than $1000 \mathrm{~g}$; the net explosive content for a combination containing fountains must not exceed $3000 \mathrm{~g}$, of which articles other than fountains must not contain more than $1000 \mathrm{~g}$; the net explosive content of a battery containing fountains shall not exceed $3000 \mathrm{~g}$. Bangers used in batteries or combinations shall not have a total net explosive content exceeding $1000 \mathrm{~g}$. Flash bangers used in batteries or combinations shall not must have a total net explosive content exceeding $250 \mathrm{~g}$. Flash bangers used in batteries or combinations must not have a total net explosive content exceeding $25 \mathrm{~g}$. 
- rockets category F2 - Not more than $75 \mathrm{~g}$; the sound and / or explosive charge, if any, shall not exceed $10.0 \mathrm{~g}$ of black powder or $4.0 \mathrm{~g}$ of the nitrate / metal composition or $2.0 \mathrm{~g}$ of the perchlorate / metal composition.

- rockets category F3 - Not more than $200 \mathrm{~g}$; the sound and / or explosive charge, if any, shall not exceed $50 \mathrm{~g}$ of black powder or $20.0 \mathrm{~g}$ of the nitrate / metal composition or $10.0 \mathrm{~g}$ of the perchlorate / metal composition.

- roman candles category F2 - Not more than $50 \mathrm{~g}$; each pyrotechnic unit not more than $10,0 \mathrm{~g}$; must not contain more than five pyrotechnic units with a sound effect composition and each of these pyrotechnic units must not contain more than $10.0 \mathrm{~g}$ of black powder or $4.0 \mathrm{~g}$ of a nitrate / metal-based sound effect composition, or 2.0 g perchlorate / metal sound effect composition.

- roman candles category F3 - Not more than $250 \mathrm{~g}$; each pyrotechnic unit, not more than $50 \mathrm{~g}$; it must not contain more than ten pyrotechnic units with a sound effect composition and each of these pyrotechnic units must not contain more than $20 \mathrm{~g}$ of black powder or $8.0 \mathrm{~g}$ of a nitrate / metal-based sound effect composition or $4,0 \mathrm{~g}$ sound effect composition based on perchlorate / metal.

Another issue to be verified, related to the composition is the nature of the chemical compounds used, there are substances that, although they have very good explosive characteristics, are not allowed for pyrotechnic mixtures, given the level of toxicity or risks related to the instability of the composition related to chemical stability, respectively physical stability.

Examples of restricted substances are those with high toxicity such as: salts based on $\mathrm{Hg}$, $\mathrm{Pb}$, arsenic, radioactive heavy metals. For the risk of physical stability, are prohibited products with pyrogenic behaviour in which self-heating can occur relatively easily, which can lead to uncontrolled ignition, or products for which is very high the sensitivity to handling, transport, assembly activities, in terms of extreme temperatures, the impact, friction, possible electrostatic discharges, or an uncontrolled reaction may occur, even under normal storage conditions, here we can mention the mixtures based on chlorate - metal powder, which is a very effective explosive, but too unstable for long storage periods. On the other hand, similar mixtures are allowed, just as effective: perchlorates - metal powders, nitrates - metal powders ( $\mathrm{Al}, \mathrm{Ti}, \mathrm{Mg})$.

The composition verification, in most cases, is done by consulting the safety data sheet and instructions, supplied by the manufacturer (in the way that they exist), or by certain determinations made in the laboratory, which may be qualitative or quantitative.

An example of equipment that can identify certain substances in the composition is the IScan LSD (Figure 2).

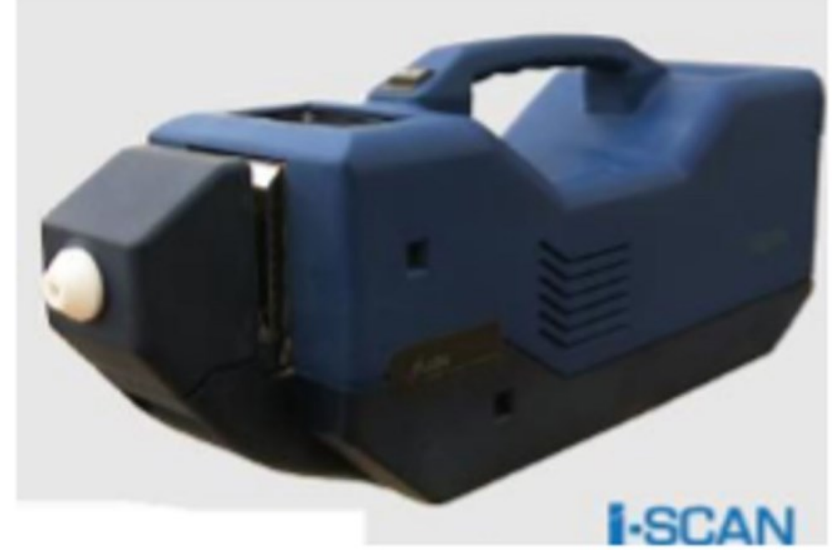

Fig.2. Equipment for the detection and examination of explosive substances, I-SCAN LSD 
The I-SCAN LSD device is designed on the principle of ionic mobility spectrometry (SMI) and can be used to examine territories, spaces, moving objects and goods at checkpoints during customs and border control, in the forensic laboratories of various departments, in the analytical laboratories of industrial enterprises and in scientific research institutions.

The operating system of the I-SCAN LSD detector analyses the spectral maximum of the examined substances based on the mathematical expectation (average of the whole) and the dispersion in time, corresponding to the maximum for the target substances taken from the system library [5].

It should be noted that European Directive no. 2013/29 / EU requires that the load of pyrotechnic articles does not contain explosives for civilian use used for shooting or military explosives, thus substances such as: nitroglycerin, trityl, tetryl, penthrite, hexogen, octogen, must NOT be found in the composition of pyrotechnic articles included in the categories of entertainment, stage or for technical purposes.

By exception, European Directive no. 2013/29 / EU allows the use of black powder or "flash" mixtures such as perchlorate - metal powder.

The figures below show various pyrotechnic articles developed in order to establish the net mass of pyrotechnic mixture (NEC) [6].

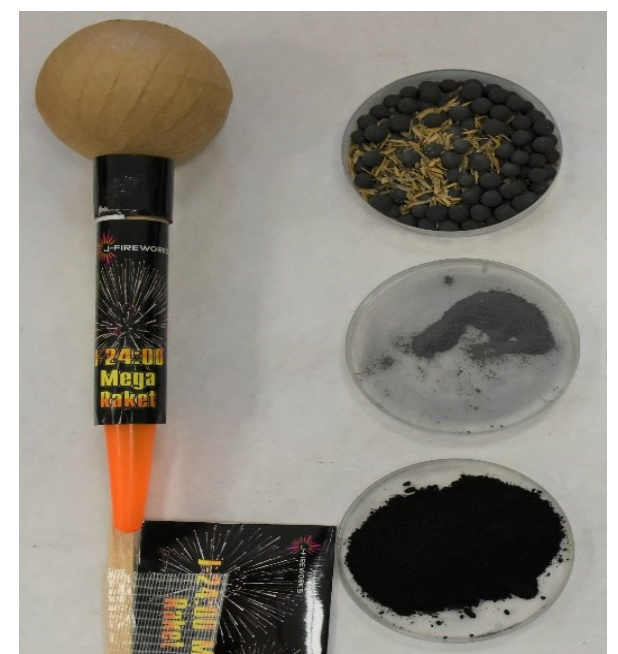

a) Rocket, cat F2

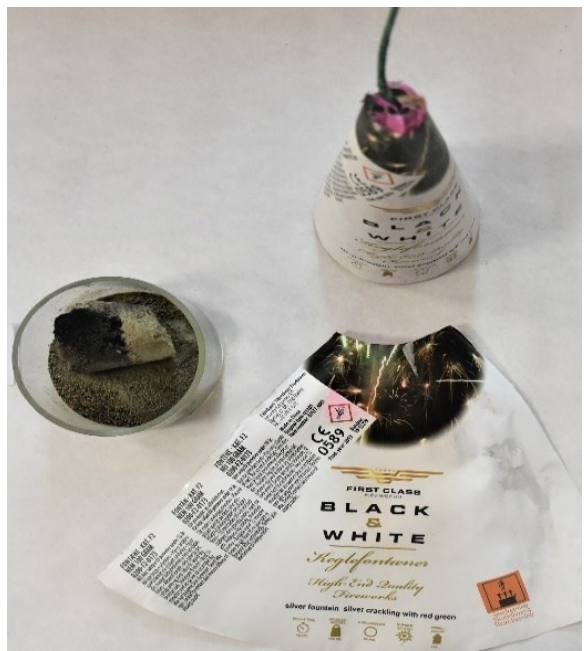

b) Fountain, cat F2

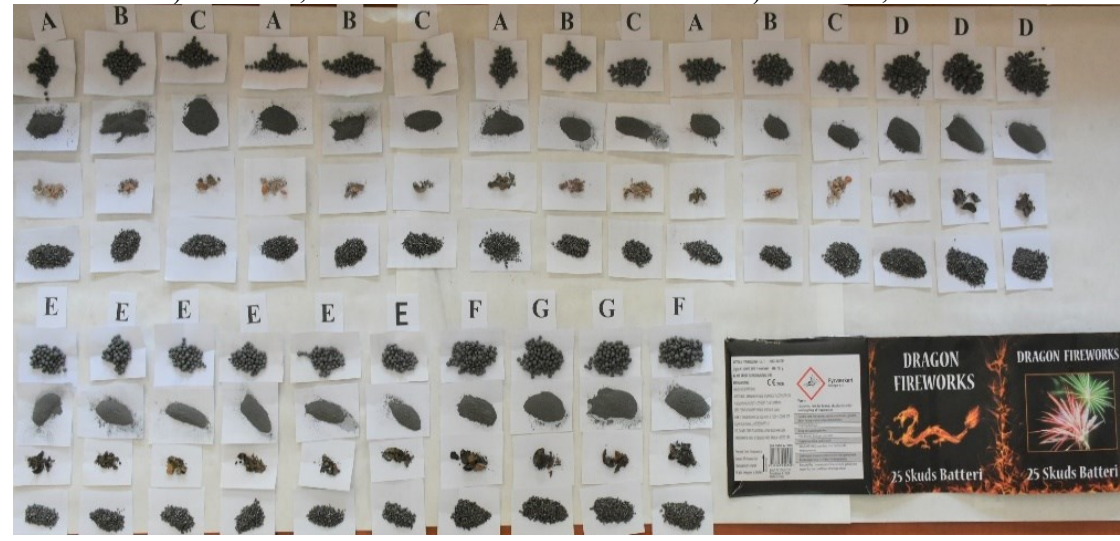

b) Shot tubes battery, cat F2 


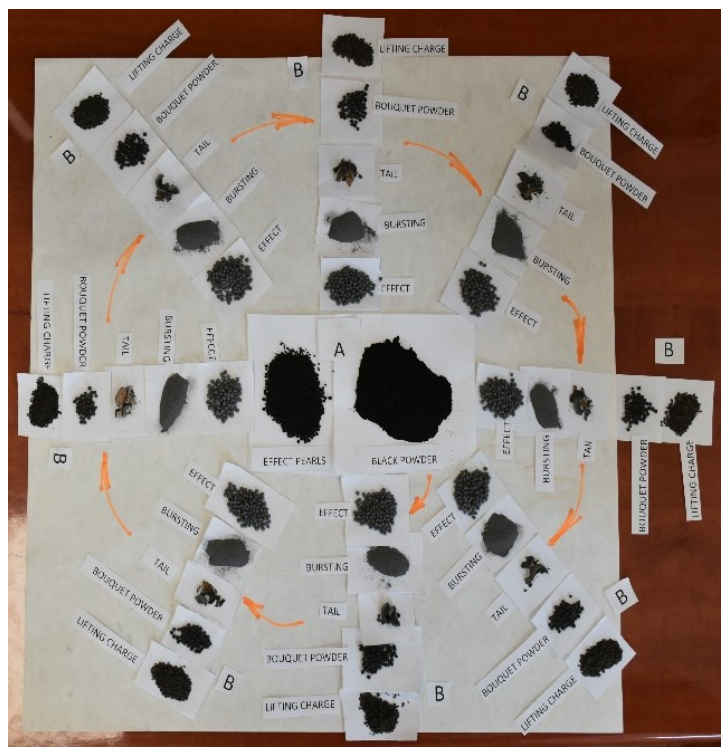

c) Shot tubes and fountain combination, cat F2

Fig. 3. Compositions of explosive materials present in various pyrotechnic articles

\subsection{Nonconformities found during performance tests.}

Certain hidden defects of the products cannot be identified during the aforementioned checks and evaluations, and will only be found when performing performance tests [4].

This test concerns the operation at the parameters declared by the manufacturer (duration of initiation, firing time, maximum permissible noise level, trajectory) and limitation of the effect inside the safety zone (burning or incandescent debris, fragments designed after destruction of the pyrotechnic article).

The tests shall be performed under real operating conditions within the manufacturer's specified temperatures, under foreseeable humidity or rain conditions, and a maximum wind speed of $5 \mathrm{~m} / \mathrm{s}$.

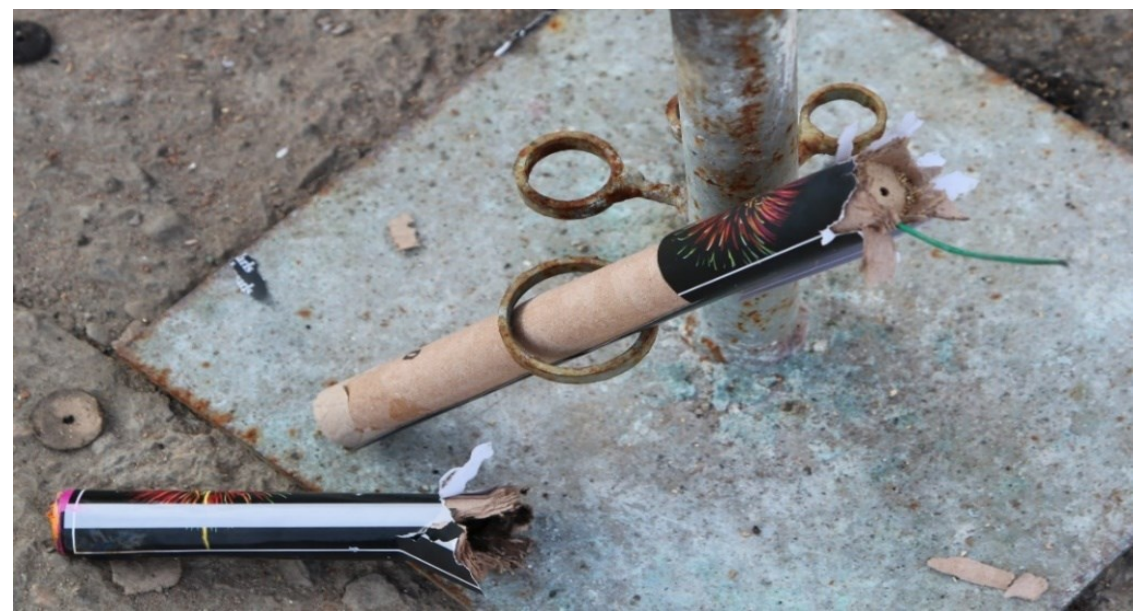

a) 


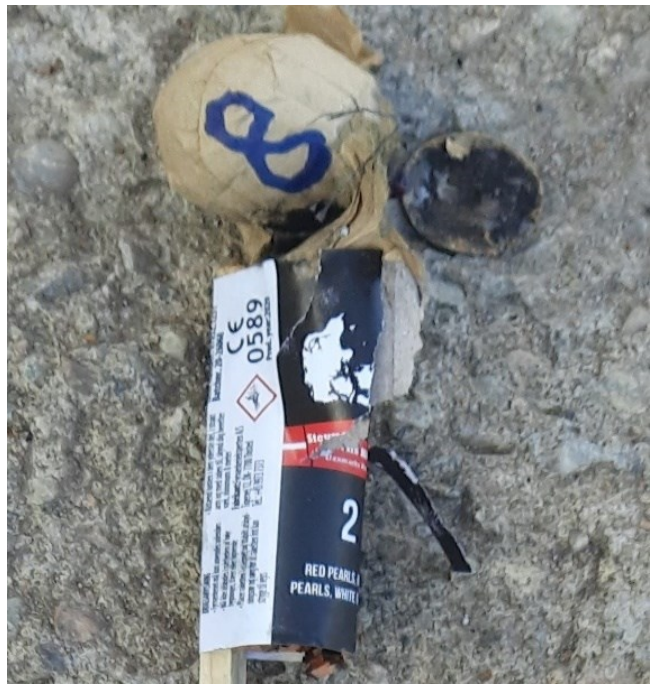

b)

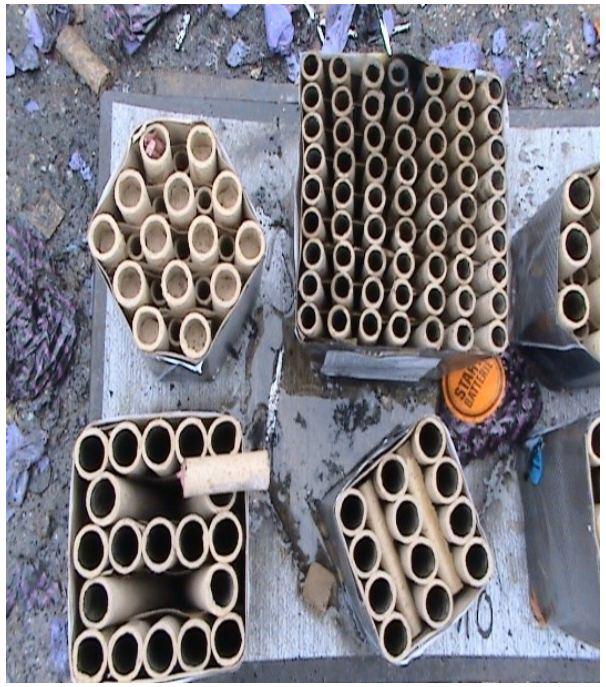

c)

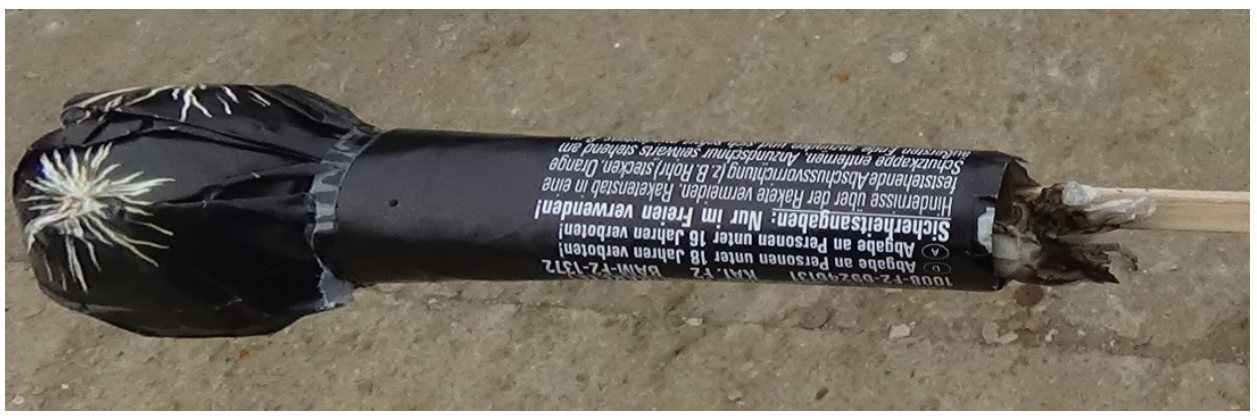

d)

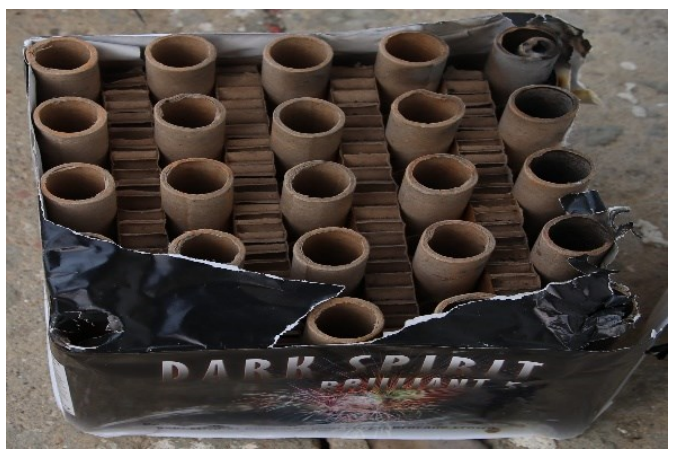

e)

Fig. 4. Examples of pyrotechnic articles with deficiencies in performance testing (a - Roman candle cat F2; b - rocket, cat F2; c - compound fireworks, cat F3; d - rocket, cat F2; e - shot tubes battery, cat F2)

Nonconformities that can be found quite frequently in products with deficiencies can be:

- ground explosion for products that must not have an explosive operation $(a, b)$;

- total failure (impossibility to activate the initiation system due to deficiencies of assembly or incorrect storage and handling) (c, d); 
- failure to comply with the initiation and safety times at the time of activation, in order to ensure the withdrawal of staff;

- operation with combustion or explosion speeds outside the range declared by the supplier / manufacturer;

- incorrect or uncontrollable trajectory;

- $\quad$ partial failure (for complex products such as batteries and combinations) (e);

- noise level exceeding $120 \mathrm{~dB}$ imposed, as a peak at the limit of the safety zone, in the wind direction;

- the risk of fire outside the prescribed safety zone;

- Generating excess smoke from items that are reported to be used indoors.

\section{Conclusions}

Following other retail markets, the pyrotechnics sector has established an extensive online retail presence making it possible for EU consumers to purchase pyrotechnic articles from web-shops based physically across the internal market.

This trend has also given rise to an increasing number of reports received by the European Commission indicating that fireworks categorised as pyrotechnic articles were reaching the general public, nonetheless, the Pyrotechnic Articles Directive 2013/29/EU provides that these articles should only be sold to and used by professional users recognised as having specialist knowledge. Moreover, the non-authorised use of pyrotechnic articles has caused concern considering the severity of some of the accidents documented and in instances where their misuse has been associated with the criminal intent to harm persons or damage property.

In view of the widespread use of pyrotechnic articles, both for entertainment purposes, as theatrical and technical applications, quality assurance of their compliance with the requirements of European Directive 2013/29 / EU and of European Standards Harmonized with it, is an activity that falls under the responsibility of regulators and supervisors. In Romania, this activity is divided between the Ministry of Interior through the General Inspectorate of the Romanian Police and the County Police Inspectorates (Weapons, Explosives and Dangerous Substances Service) and the Ministry of Labour through the Labour Inspectorate and county branches (county ITMs).

Following the identification of pyrotechnic articles with major or critical nonconformities, as a result of their tests and expertise, the national authorities took measures to withdraw from the market and ordered their destruction and, where appropriate, the prosecution of those guilty of disposal on the market of these items with a high risk of accidents.

Considering that these regulatory and control institutions do not have the possibility to perform the verifications from a technical point of view, INCD-INSEMEX Petroșani is engaged through the Specialized Laboratory (accredited by RENAR and recognized at European level) to carry out these tests and evaluations.

At the request of the authorities, the INSEMEX Specialized Laboratory also evaluates objects of unknown origin, some handcrafted, to determine whether they fall under the legislation on explosives, including the determination of the level of risk and their functionality.

Following the international and especially European recognition, INCD-INSEMEX Petroșani collaborated with other EU or third Member States (e.g. Turkey) either for evaluation for the certification of pyrotechnic articles or for batch verifications, at the request of the authorities of these EU member states, authorities responsible for market inspection. 


\section{References}

1. Rus D., Vasilescu GD, Kovacs A., Gheorghiosu E., Jitea C., Informatical (IT) platform for the certification of explosives and pyrotechnical products, Environmental Engineering and Management, ISSN 1582-9596, Environmental Engineering and Management Journal (EEMJ), June, vol.16, No.6, p.1361-1366, ISSN 1582-9596, (2017). http://omicron.ch.tuiasi.ro/EEMJ

2. Howard A., Study on illegal sales of pyrotechnic articles destined for professional users (category F4) to the general public, Luxembourg: Publications Office of the European Union, ISBN 978-92-76-02686-0, DOI: 10.2873/352706, (2019)

3. Jitea C., Kovacs A., Vasilescu, G., Gheorghiosu E., Rus D., Bordos, S., Prospective analysis of ambiental and weather effects on conform displaying of fireworks, 8th INTERNATIONAL CONFERENCE ON MANUFACTURING SCIENCE AND EDUCATION (MSE 2017) TRENDS IN NEW INDUSTRIAL REVOLUTION, Book Series: MATEC Web of Conferences, Volume: 121, Article Number: UNSP 11011, DOI: 10.1051/matecconf/ 201712111011, Published: (2017)

4. Vasilescu G.D., Laszlo R., Kovacs A., Radeanu C., Miclea O., Prospective and exploratory research in the quality field of industrial risk assessment and analysis, QUALITY-ACCESS TO SUCCESS, Volume: 20, Pages: 43-48, Supplement: 1, Published: (JAN 2019)

5. C. Rădeanu, A. Kovacs, D. Rus, I.C. Jitea, G. D. Vasilescu, Increase in the security quality in use of professional pyrotechnic articles falling in category F4 QUALITY-ACCESS TO SUCCESS, Volume: 20, Pages: 83-88, Supplement: 1, Published: (JAN 2019)

6. Vasilescu G, Laszlo R; Kovacs A, Jitea IC, Rus D, Radeanu C, Miron C Determination of threats traceability in the use of explosive materials in different environments, 9TH INTERNATIONAL CONFERENCE ON MANUFACTURING SCIENCE AND EDUCATION (MSE 2019): TRENDS IN NEW INDUSTRIAL REVOLUTION, Edited by:Bondrea, I; Cofaru, NF; Inta, M, Book Series: MATEC Web of Conferences, Volume: 290, Article Number: 12029, DOI: 10.1051/matecconf/ 201929012029, Published: (2019), Location: Sibiu, ROMANIA, JUN 05-07, (2019), ISSN 1582-2559

7. Jitea IC, Vasilescu GD, Rus DC, Radeanu C, Bordos S, Improving the safety level of pyrotechnic articles testing in variable conditions of microclimate, ENVIRONMENTAL ENGINEERING AND MANAGEMENT JOURNAL, Volume: 18, Issue: 4, Pages: 839845, Published: (APR 2019), SSN: 1582-9596, eISSN: 1843-3707 